\title{
Rainfall-Induced Landslide Thresholds Development by Considering Different Rainfall Parameters: A Review
}

\author{
Abdul Muaz Abu Mansor Maturidi', Norhidayu Kasim', Kamaruddin Abu Taib², \\ Wan Nur Aifa Wan Azahar ${ }^{1}$ \\ 1 Department of Civil Engineering, Kulliyyah of Engineering, International Islamic University Malaysia, \\ Jalan Gombak, 53100, Selangor, Malaysia \\ 2 Department of Civil and Structural Engineering, National University of Malaysia, 43600 Bangi, \\ Selangor, Malaysia \\ * Corresponding author's e-mail: ayukasim@iium.edu.my
}

\begin{abstract}
This paper reviews the development of landslide thresholds from the perspective of rainfall and climate patterns. For certain, geology, morphology, lithology, etc., contribute to the initiation of the mass movement. However, the role of rainfall as the triggering mechanism of the landslide is vital as well. It has been proven by many researchers from various studies worldwide that have proposed the rainfall thresholds by utilising different rainfall parameters. The outcome of their studies is interesting, since different regions have diversified patterns of rainfall that produce a variety of threshold models. Therefore, from various published papers on rainfall thresholds, this paper studied the variety of rainfall parameters that have been utilised in establishing the rainfall threshold for landslide prediction. Instead of providing a better understanding regarding the application, this review aimed to cultivate the following study for deriving rigorous parameters for the purpose of sustainable findings.
\end{abstract}

Keywords: rainfall threshold, landslides, rainfall parameters, empirical, correlation

\section{INTRODUCTION}

A landslide is a disastrous event that occurs in every region worldwide. This catastrophe leaves a huge impact on the environment and human beings since it claims thousands of lives as well as deteriorates the buildings and infrastructures (Valenzuela et al., 2019). Landslides can be triggered either by earthquakes, man-made, snowmelt, or extreme precipitation (Kazmi et al., 2016). However, these triggering aspects should be incorporated with other significant factors contributing to the landslide, such as geological, morphological, lithological, etc. This is because different regions may experience different causes of slope failure (Guzzetti et al., 2007; Vaz et al., 2018). Therefore, a clear recognition of the landslide cause would be identified according to this circumstance.

It is agreed that different factors may trigger the landslide. However, the effect of rainfall in triggering slope failure has been broadly argued among researchers. This leads to developing a rainfall threshold that performs a reasonable indicator for predicting the upcoming landslides (Dahal \& Hasegawa, 2008; Dikshit et al., 2019). The concept of rainfall threshold was pioneered by Caine (1980), who performed the correlation between the rainfall parameters and the debris flow by developing the global empirical rainfall intensity-duration (I-D) threshold. However, before that, Endo (1969) initiated the study of a minimum amount of rainfall that triggered the landslide. It was then followed by Onodera et al. (1974) who performed a qualitative analysis of rainfall that is useful as the landslide triggering mechanism. After all, Caine (1980) laid the groundwork for the rainfall threshold that is widely applicable worldwide in the present day. Ideally, the concept of rainfall threshold is a curve that isolates the rainfall intensity in between the failure zone 
(landslide) and the stability zone (Crozier, 1997). Moreover, the definition of a threshold is explained in detail by (Reichenbach et al., 1998). For a process to occur or the condition to alter, it must surpass or reach the minimum or maximum level. The state does not change when it meets the minimum threshold underneath the lowest level, while a process always occurs when it exceeds the above-mentioned level of maximum threshold (Crozier, 1997; Dahal \& Hasegawa, 2008).

Moreover, different researchers utilised various rainfall parameters to develop the rainfall threshold. For instance, the rainfall intensityduration (I-D) threshold applies the power-law best-fit regression (Napolitano et al., 2016; Nikolopoulos et al., 2014). The respective threshold was performed in a full logarithmic scale graph, whereby the rainfall intensity represents the abscissa. In contrast, the rainfall duration is subjected to the ordinate axis, and both parameters are presented in a scatter plot. The equation of the I-D threshold curve is manifested as $I=\alpha D^{-\beta}$, whereby $\mathrm{I}$ is defined as rainfall intensity, D represents the rainfall duration, while the threshold coefficient derived from the power-model application are characterised for both $\alpha$ and $\beta$ values. On the other hand, the utilised rainfall parameter for the proposed rainfall threshold may be derived from different techniques. For instance, Caine (1980) considered the mean rainfall intensity, $\mathrm{I}_{\text {mean }}$ from the division of cumulative rainfall event, $\mathrm{E}$ by rainfall duration, $\mathrm{D}$, while some authors applied peak or maximum hourly rainfall intensity, $\mathrm{I}_{\max }$ in developing the I-D threshold (Leonarduzzi et al., 2017; Norhidayu Kasim et al., 2020). Gariano et al. (2015) utilised the cumulative event rainfall to develop a cumulative rainfall event-duration (E-D) threshold. However, the threshold could be developed using the relevant rainfall parameters, including mean rainfall intensity, maximum rainfall intensity, cumulative rainfall, and antecedent rainfall (Dahal \& Hasegawa, 2008).

Besides, the spatial factors greatly influence the rainfall threshold regarding the study area and rain gauge selection. The scope of investigated area for the rainfall threshold is vast, where it can cover from the smallest region up to the entire globe. Segoni et al. (2018) categorised the spatial scale of landslide starting from a single slope, local, basin, regional, national, continental, and global. The diversity of spatial factors is greatly affected by the geological, geomorphological, hydrological, and lithological characteristics of the study area. However, the larger the spatial scale, the higher level of complexity that needs to be handled for acquiring the meteorological data. Besides, the selection of a rain gauge that closes to the landslide scene is being discussed as well. Few works stressed the effect of retrieving the precipitation data from different rain gauges at the time of slope failure (Nikolopoulos et al., 2014). The significant relation of the plot sample was discovered for the range of meteorological stations for less than 10 to $15 \mathrm{~km}$ by correlating the mutual distance of rain gauges and the maximum difference in the normalised hourly rainfall (Aleotti, 2004).

Similarly, Melillo et al. (2018) decided to select the rain gauge according to the geographical features. A rain gauge of less than $5 \mathrm{~km}$ is specified for hilly or valley areas, while the rain gauge of less than $15 \mathrm{~km}$ is applied to the low-relief or flat area. For the temporal consideration, the availability of meteorological data corresponding to the landslide event are prioritised for the analysis purposes. Usually, the temporal scale deals with the duration of a rainfall event measured either in hourly, daily, weekly, monthly or yearly units. For instance, hourly rainfall is applied to determine the specific rainfall event that has led to the slope deterioration.

Moreover, Dahal and Hasegawa (2008) converted the daily into hourly rainfall using the formula proposed by Shakya (2002), which indicates a significant relation between both scales. Besides, the daily or monthly rainfall is being captured to accumulate the rainfall to determine the effect of antecedent and mean rainfall. Meanwhile, the Mean Annual Precipitation (MAP), representing the yearly rainfall, is utilised to normalise the critical, maximum, or mean rainfall intensity.

Other than that, some authors reflect on the regional season as the scope and limitation of the research. For example, Cannon, Gartner, Wilson, Bowers, and Laber (2008) established several rainfall thresholds based on the summer and winter seasons for southwestern Colorado and Southern California. Meanwhile, some authors developed the rainfall thresholds according to the landslides during the rainy season, especially for the mid-latitude region (Gabet et al., 2004; Dikshit et al., 2019). Nevertheless, this scope may not be appropriate for other regions because the 
landslide can occur within the dry season if extreme showers sporadically hit the prone area of landslides. Therefore, the meteorological data that correspond to the landslides for the entire twelve-month period are also admissible.

In addition, Guzzetti et al. (2007) classified a few types of existing rainfall thresholds according to various studies, such as Rainfall Intensity-Duration (I-D), the most applied rainfall threshold. It is then followed by Rainfall Event-Duration (E-D), Rainfall Cumulative (R), and Cumulative Rainfall Event-Rainfall Intensity (E-I) (Guzzetti et al., 2007; He, Wang, \& Liu, 2020). The distinct rainfall parameters in developing the rainfall threshold can be an excellent measure to obtain the most accurate threshold from comprehensive validation, comparison, and so forth. Then, to enhance the rainfall threshold, numerous studies emphasise normalising the rainfall intensity with the average yearly rainfall (MAP), which is beneficial to relate the derived threshold according to the overall condition for selected case studies.

Besides, this rainfall threshold is relevant for estimating the shallow landslide and debris flow (Caine, 1980; Giannecchini et al., 2012; J. Huang et al., 2015). The main reason is that any type of landslides is usually triggered by high-intensity rainfall (Lazzari \& Piccarreta, 2018). Therefore, the relation between the rainfall and the shallow landslide is reasonable since that type of landslide had generated a temporary aquifer and increased the perched water table into the ground layer from the intense precipitation, which eventually causes the failure within the depth in between $0.5 \mathrm{~m}$ to $5.0 \mathrm{~m}$ (Dahal \& Hasegawa, 2008; Zêzere et al., 2015). However, several studies analysed the effect of rainfall on the deep-seated landslide that is usually caused by the constant prolonged rainfall since that type of failure is rooted from a deeper layer (beyond $5 \mathrm{~m}$ ) and greatly affected by the tectonic impact (Dahal \& Hasegawa, 2008; Uchida et al., 2013). Anyhow, some studies integrated both landslide types (shallow and deep-seated landslide) to evaluate the comparability of the results from the rainfall measurement (Zêzere et al., 2005).

Subsequently, the rainfall threshold could later be pragmatised into the application of a warning system to mitigate the landslide losses (Aleotti, 2004; Piciullo et al., 2016; NolascoJavier \& Kumar, 2017; He et al., 2020). In the systematic threshold model including the application of statistical indices, operating procedure, and comprehensive validation from rainfall input such as the maximum, minimum intensity, normalised precipitation that corresponds to the average yearly rainfall and the antecedent rainfall, a certain threshold could be practically implemented in the warning system. Once the threshold model is fully integrated with the warning devices through sophisticated technology, it would enable the authorities to conduct pre-emptive measures to save lives and properties if any disaster is predicted to occur. In order to achieve that, a comprehensive analysis must be taken into account. For example, by further calibrating and upgrading the rainfall threshold using the application of receiver operating characteristics (ROC) metrics, the susceptibility model of a landslide as a mechanism of early warning system can be validated through four types of ROC namely True Positive Rate, False Positive Rate, False Alarm Rate and Threat Score (Vaz et al., 2018). Eventually, the reliability of the I-D threshold will be evaluated from the application of LEWS.

This review paper identified the various rainfall parameters used for developing rainfall thresholds. For past reference, several authors have elucidated the critical review for the overall aspect of rainfall thresholds, such as Guzzetti et al. (2007), Zêzere et al. (2015), Segoni et al. (2018), and Dikshit et al. (2020), but this paper scrutinised the variety of rainfall parameters and existing developed thresholds presented by various authors.

\section{TYPE OF RAINFALL THRESHOLDS}

As it was stated earlier, several rainfall thresholds have been presented by different studies. However, the first step is to differentiate between the methods of developing the rainfall thresholds. Two approaches, namely empirical or physical, could establish the rainfall threshold (Dahal \& Hasegawa, 2008; Guzzetti et al., 2007). Fig. 1 depicts the flow of the rainfall threshold model compiled by Guzzetti et al. (2007). In general, the full utilisation of meteorological data corresponding to the occurrence and non-occurrence of landslide events is an approach for a practical method (Aleotti, 2004; Nikolopoulos et al., 2014; Zêzere et al., 2015).

Two methods are applicable for the empirical variant, which are the practical and statistical approaches (Nikolopoulos et al., 2014). The 
historical landslide with adequate rainfall data is required for the empirical method. Nevertheless, there are still no restrictions in terms of the selection of landslide period (e.g., 20 years or 30 years historic landslide) and the total landslide cases required. The limitation is quite impossible since not necessarily all the collected meteorological data are available for analysis. For instance, the rainfall data for the old landslide is commonly unavailable. Another issue is regarding the rain gauge that breaks down during the occurrence of landslide due to the extreme showers, which can cause an error in acquiring the necessary rainfall data corresponding to the landslide event.

For the issue of total landslide cases required, it still seemed to vary for each study. For instance, Dahal and Hasegawa (2008) gathered 677 historical landslide cases for Nepal Himalaya, but only managed to have only 193 cases out of 677 subjected to meteorological information availability. Caine (1980) collected around 73 cases of global landslides, and Chen et al. (2015) selected 156 landslide cases triggered by precipitation. Therefore, selecting the range of landslide periods and the total landslide cases is still considered relevant. Still, few studies comply with the range of landslide periods such as Marchi et al. (2002) who performed a ten-year debris flow threshold. This limitation for the period of landslides may be influenced by the climatic change and morphological condition of research areas.
Despite that, according to Nikolopoulos et al. (2014), practical methods are essential in establishing the threshold from the visual inspection or direct correlation of meteoric events that consist landslide or debris flow. Once the landslide parameters have been derived and plotted to scatter in the logarithmic graph, the best fit line that is compatible with the plot pattern will be generated. On the other hand, associating the precipitation data with probabilistic models to generate the threshold is an approach in adopting the statistical method. For instance, statistical methods such as the Frequentist method, Bayesian inference, and quantile regression have been established by Brunetti et al. (2010), Guzzetti et al. (2007), as well as Saito et al. (2010), respectively.

Meanwhile, physically-based thresholds involve numerical techniques to identify the relation of rainfalls, pore pressure, and slope stability (Aleotti, 2004; Nikolopoulos et al., 2014). This physically based model associates the pattern of rainfall with the state of slope stability/ instability in the scope of infiltration models (Guzzetti et al., 2007). In general, the process involved the estimation of the accumulated water that infiltrates into the ground (Zêzere et al., 2015). It deals with the quantity of the water that infiltrated into the soil and the discharge of water in the time of failure to identify the amount of pore water pressure that the slope instability has encountered. Even though there are new methods proposed from the

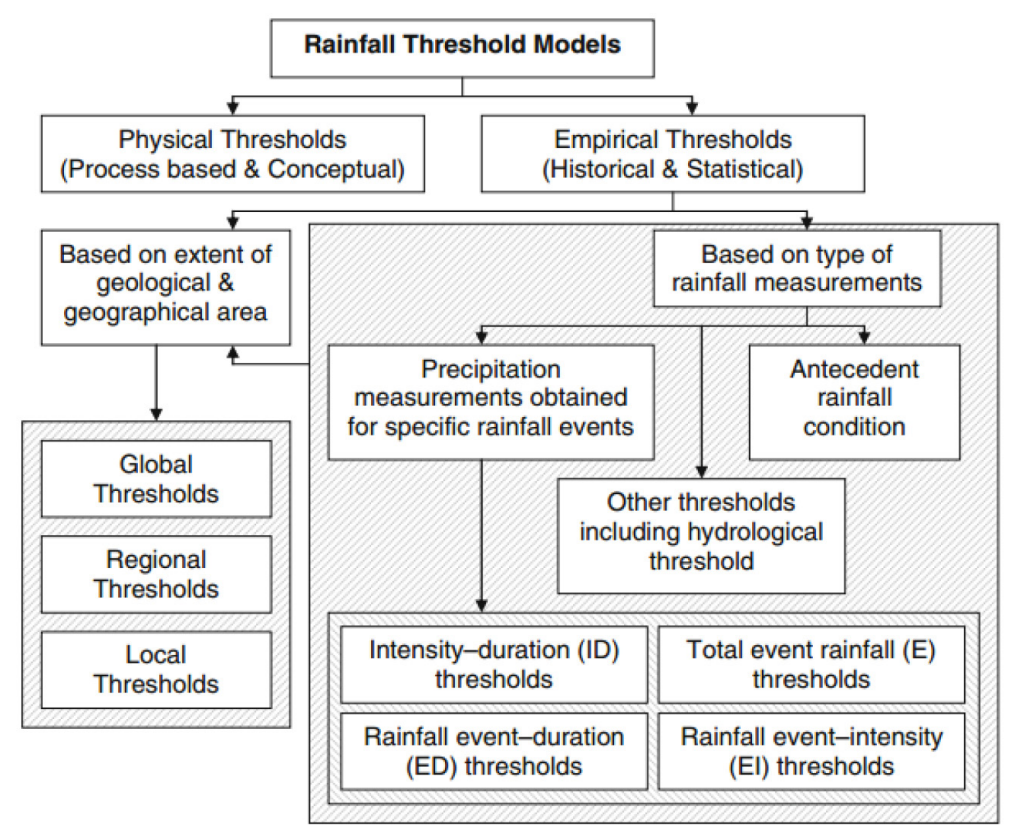

Figure 1. Various models of rainfall thresholds recognized by Guzzetti et al. (2007), (Source by: (Kanungo \& Sharma, 2014)) 
advancement of the numerical model, monitoring devices, and laboratory equipment, this physically based threshold still requires high-cost hydrological and geotechnical data that are irrelevant for entry research (Giannecchini et al., 2012). This is due to the complexity of acquiring the data from the landslide in large or rural areas or from the old landslide events.

Therefore, the empirical methods seem to be more convenient than the physical method, even though there are few uncertainties in spatial and temporal factors. For instance, the rainfall intensity measured at the proximity rain gauge at the time of landslide may not be the same as the intensity at the scene. This may be affected by the change in elevation that led to the variation of wind direction for the precipitation to take place (Nikolopoulos et al., 2014). Even two different locations at the same elevation (e.g. highland terrain) could experience dissimilar rainfall due to the landform variation. The same ambivalent in rainfall measurement can occur in a larger flat area. Hence, it is essential to vary the rainfall analysis (e.g., normalising the rainfall concerning MAP) so that the developed rainfall threshold is dependable.

In addition, Table 1 demonstrates the type of rainfall parameters with the abbreviations and symbols that have been presented by various authors and studies. The different types of rainfall parameters were already compiled by Guzzetti et al. (2007). However, this paper revised the list of authors that inherit the rainfall parameters from the pioneering authors for the past ten years (2010-2020).

\section{Intensity -Duration (I-D) Threshold}

A great number of studies apply this rainfall intensity-duration (I-D, hereinafter) threshold. As stated earlier, the I-D threshold graph is formed in either semi-log or log-log graphs. This I-D threshold is a pioneering work of Campbell (1978) and Caine (1980). Caine (1980) developed the Global I-D threshold by considering 73 debris flow cases from various authors. According to Caine (1980), the total rainfall event-induced debris flow, E $(\mathrm{mm})$ has been divided by the rainfall duration, D (hours), which has resulted in the mean rainfall intensity, $\mathrm{I}_{\text {mean }}(\mathrm{mm} / \mathrm{h})$. In utilizing the rainfall intensity with regards to the rainfall duration in a power regression model, the I-D threshold formula is expressed as:

$$
I=\alpha D^{-\beta}
$$

Where rainfall intensity, I is denoted in $\mathrm{mm} / \mathrm{h}$, the duration of precipitation, D is specified in

Table 1. Variables used in developing Rainfall Threshold (compiled after Guzetti et al. (Guzzetti et al., 2007))

\begin{tabular}{|c|c|c|c|}
\hline Variables & Explanation & $\begin{array}{l}\text { Scale or } \\
\text { Units }\end{array}$ & $\begin{array}{c}\text { Succeeded by } \\
\text { (only selected one study } \\
\text { out of many) }\end{array}$ \\
\hline I & $\begin{array}{l}\text { Rainfall intensity, the amount of precipitation over the considered } \\
\text { rainfall duration, also known as mean rainfall intensity, } I_{\text {mean }}\end{array}$ & $\mathrm{mm} / \mathrm{h}$ & (Nikolopoulos et al., 2014) \\
\hline$I_{\max (h)(d)}$ & $\begin{array}{l}\text { Maximum rainfall intensity, the highest rainfall intensity in the } \\
\text { rainfall event }\end{array}$ & $\mathrm{mm} / \mathrm{h}$ & $\begin{array}{l}\text { (Norhidayu Kasim et al., } \\
\text { 2020) }\end{array}$ \\
\hline$I_{\text {peak }}$ & $\begin{array}{l}\text { Peak rainfall intensity, the top rainfall rates that have resulted in the } \\
\text { landslides, almost similar to } I_{\max }\end{array}$ & $\mathrm{mm} / \mathrm{h}$ & (Chen et al., 2015) \\
\hline $\mathrm{I}_{\mathrm{cr}}$ & Critical Rainfall Intensity & $\mathrm{mm} / \mathrm{h}$ & (Giannecchini et al., 2012) \\
\hline $\mathrm{I}_{\mathrm{CAR}}$ & $\begin{array}{l}\text { Critical rainfall intensity extracted from calibrated antecedent } \\
\text { rainfall }\end{array}$ & $\mathrm{mm} /$ day & (Garcia-Urquia, 2016) \\
\hline $\mathrm{I}_{\text {MAP }}$ & $\begin{array}{l}\text { Normalized rainfall Intensity, the rainfall intensity divide by MAP, } \\
\left(\mathrm{I}_{\text {MAP }}=\mathrm{I} / \mathrm{MAP}\right)\end{array}$ & $1 / \mathrm{h}$ & (Zhou \& Tang, 2014) \\
\hline $\mathrm{E}$ & $\begin{array}{l}\text { Critical Cumulative Rainfall Event, the accumulated precipitation } \\
\text { measured from the starting of rain to the occurrence of landslide }\end{array}$ & $\mathrm{mm}$ & (Dikshit et al., 2019) \\
\hline $\mathrm{E}_{\mathrm{MAP}}$ & $\begin{array}{l}\text { Normalized Cumulative Rainfall Event, the critical cumulative event } \\
\text { over the MAP, }\left(E_{M A P}=E / M A P\right)\end{array}$ & - & (He et al., 2020); \\
\hline $\mathrm{R}$ & Daily Rainfall, the intraday rainfall that has resulted in the landslide, & $\mathrm{mm}$ & (Yang et al., 2020) \\
\hline A & $\begin{array}{l}\text { Antecedent Rainfall, the rainfall in the days immediately preceding } \\
\text { a landslide even, measured in days }\end{array}$ & $\mathrm{mm}$ & (Ma, Li, Lu, \& Wang, 2014) \\
\hline MAP & Mean Annual Precipitation, the yearly average of rainfall & $\mathrm{mm}$ & $\begin{array}{l}\text { (Nolasco-Javier \& Kumar, } \\
\text { 2017) }\end{array}$ \\
\hline $\mathrm{D}$ & Duration of rainfall event & h or days & (Peruccacci et al., 2017) \\
\hline $\mathrm{D}_{\mathrm{cr}}$ & Duration of critical rainfall event which has triggered the landslides & $\mathrm{hr}$ & (Zhou \& Tang, 2014) \\
\hline$D_{E}$ & Duration of cumulative rainfall event & $\mathrm{h}$ or days & (Gariano et al., 2015) \\
\hline
\end{tabular}


(hour or day). At the same time, $\alpha$ and $\beta$ represent the constant for the depth of rainfall and threshold inclination. Other researchers, such as Jibson (1989) and Guzzetti et al. (2008), managed to revise the global I-D threshold with a different threshold value. Meanwhile, the total rainfall event that had triggered the landslide was the critical rainfall, $E_{c r}(\mathrm{~mm})$. The definition of rainfall parameters has been explained in detail, such as the measurement of critical duration that elapses from the initial rainfall time until the shallow landslide.

In contrast, critical rainfall is the accumulated rainfall from that critical duration. The initial time of rainfall is measured prior to a minimum of 24 consecutive hours of the inter-event period without rainfall or known as the Non-Rainfall Gap (NRG). The value is very sensitive to the threshold, because it would determine the exact rainfall duration (Guzzetti et al., 2007).

After that, the cumulative critical rainfall with the critical duration is divided to obtain the mean rainfall intensity, $\mathrm{I}_{\text {mean }}$, which eventually generates the I-D threshold from those parameters (mean rainfall intensity and critical duration). The way they extract the rainfall data and develop the threshold is more or less the same as the pioneering work of Caine (1980). However, they emphasized more regarding the approach to extract the rainfall parameters with specific terms.

For most of the studies, the rainfall intensity (I) used in developing in I-D threshold, determined as mean rainfall intensity, $\mathrm{I}_{\text {mean }}$ (Chen et al., 2015; Nikolopoulos et al., 2014). However, from another point of view, Leonarduzzi et al. (2017) mentioned the maximum daily rainfall intensity, $I_{\max (d)}$ can be a good parameter in predicting the landslides in the region of Switzerland. Likewise, Aleotti (2004) mentioned the value of maximum hourly rainfall intensity, $\mathrm{I}_{\max (\mathrm{h})}$, that induces the mass movement, but he did not use that parameter to develop the I-D threshold; rather, he utilized the mean rainfall intensity. In contrast, Norhidayu Kasim et al. (2020) have considered the maximum hourly rainfall intensity, $I_{\max (\mathrm{h})}$ instead of other rainfall parameters to develop I-D threshold of Peninsular Malaysia because that maximum intensity is the factor that tends to contribute to the state of slope instability. Then, in general, the application of mean rainfall intensity, $\mathrm{I}_{\text {mean }}$ in the I-D threshold, is to come up with uniformly distributed rainfall in conjunction with the duration of precipitation that causes the slope failure.
However, in certain cases, the intermittent or non-continuous precipitation may occur during the event of rainfall that triggers the landslide, and using mean rainfall intensity, $I_{\text {mean }}$ in the I-D threshold may result in a significant low average of rainfall intensity, which does not achieve the actual concept of rainfall threshold.

Considering the maximum rainfall intensity, $I_{\max }$ as the parameter in I-D threshold is debatable as well. In general, the notion of 'maximum rainfall intensity' is the extreme or intense rainfall that turns up just before the landslide occurrence. However, due to the spatial and temporal limitations, this state scarcely happens for most cases. This leads to some uncertainties in extracting this parameter. For example, from the perspective of hourly rainfall, there may be a circumstance where the maximum intensity is found at the initial time of the rainfall event that induces the landslide instead of just before the slope failure. Secondly, there is a case where the high rainfall intensity is constantly measured several hours before the occurrence, rather than only a single maximum hourly intensity found within the rainfall event. Both conditions do not meet the actual concept of maximum intensity, but they have a constructive argument in terms of the geotechnical stance, such as pore pressure, type of soil, soil moisture, and so forth. Hence, using this maximum rainfall intensity is considered legitimate for developing the empirical I-D threshold.

Besides, several studies have discovered the application of antecedent rainfall in developing an empirical I-D threshold (Zêzere et al., 2005; Marques et al., 2008). Associating the return period (Gumbel's law) in the evaluation of the cumulative antecedent rainfall (e.g. (1-15 days), (1-3 months)), the parameters of rainfall intensity, $\mathrm{I}_{\mathrm{CR}}$ and critical duration, $\mathrm{D}_{\mathrm{CR}}$ were obtained through the reconstruction of absolute antecedent rainfall. The I-D threshold established from this method is expressed as critical rainfall intensity, $\mathrm{I}_{\mathrm{CR}}$, (in the unit of $\mathrm{mm} /$ day), while critical rainfall duration, $\mathrm{D}_{\mathrm{CR}}$ is specified in "day" (Habibah et al., 2013). Contrary to other studies that expressed the measurement of precipitation in $(\mathrm{mm} / \mathrm{h})$ concerning its rainfall duration (hour), an approach using a large scale can differentiate between a shallow landslide or a deep-seated landslide. It is proven, since Zezere et al. (2005) stated that the (1-15 day) precipitation cause the shallow translational landslide, while (1-3 month) or longer rainfall event could trigger a deeper landslide. The term 
'critical' introduced by Zezere et al. (2005) is totally different as compared to Aleotti (2004). Aleotti (2004) extracted the critical rainfall intensity from the analysis specific rainfall event that triggered the landslide, while Zezere et al. (2005) selected the critical intensity based on high return period value related to the antecedent rainfall.

\section{Normalized Intensity-Duration $\left(N_{-}-D\right)$ Threshold}

According to Dahal and Hasegawa (2008), since some landslides were determined at low intensity subjected to the nearest rain gauge, even the specific location of the failure received an abundance of rainfall before the landslide episode led to the uncertainty for the threshold relation. Therefore, by normalising the rainfall intensity with respect to average yearly precipitation (MAP), a credible normalised ( $\left.\mathrm{N}_{\mathrm{I}}-\mathrm{D}\right)_{\mathrm{MAP}}$ threshold could be developed. The rainfall intensity, I is rescaled by the MAP to obtain the normalised intensity, $\mathrm{N}_{\mathrm{I}}$ which eventually develops the normalised $\left(\mathrm{N}_{\mathrm{I}}-\mathrm{D}\right)_{\text {MAP }}$ threshold. The normalised $\left(\mathrm{N}_{\mathrm{I}^{-}}\right.$

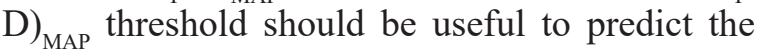
landslide since it considers the overall rainfall of the study area. Similarly, normalising I-D rainfall with the MAP is essential, since it could slightly reduce the variation of rainfall intensity (Zhou \& Tang, 2014).

On the other hand, different authors utilised various rainfall records of MAP. For instance, 30-years of MAP were applied by He et al. (2020), while Saito et al. (2008) selected 3-years of MAP (2006-2008). There is no certain limitation for the scale of MAP, since it may consider the range of period for the selected landslides, the effect of hydroclimatic of the study area or the availability of present data.

The parameters in the normalised $\left(\mathrm{N}_{\mathrm{I}}-\mathrm{D}\right)$ MAP threshold are expressed as normalised intensity, $\mathrm{N}_{1}$ or $\mathrm{I}_{\mathrm{MAP}}$ in $(1 / \mathrm{h}$ or $\mathrm{h}-1)$, and Duration, D (hour). This MAP-related landslide-threshold has been worked out by multiple authors (Dahal \& Hasegawa, 2008; Guzzetti et al., 2007; Saito et al., 2010). Aleotti (2004) presented the application of Normalised Critical Rainfall (NCR) that is derived from the ratio between the critical rainfall and the mean annual precipitation (MAP). The equation of NCR that is denoted in percentage may represent the rainfall parameters (rainfall intensity, rainfall duration and MAP) concurrently (Dahal \& Hasegawa, 2008; Guzzetti et al., 2007). Moreover, to further carry out NCR,
Aleotti (2004) proposed the correlation between normalised critical rainfall and normalised antecedent rainfall. However, based on the results, no significant correlation exists between the critical and antecedent. Meanwhile, other authors just demonstrated the term of normalised $\left(\mathrm{N}_{\mathrm{I}}-\mathrm{D}\right)$ MAP threshold instead of NCR. Overall, the general concept of normalised rainfall is almost the same, where the percentage of MAP can estimate the rainfall intensity for a landslide that is likely to occur (Dahal \& Hasegawa, 2008). This component can be included in the threshold model for the application of a landslide early warning system.

\section{Cumulative Rainfall Event - Duration (E-D) Threshold}

Several authors considered the total or cumulative rainfall in developing the rainfall threshold. The role of the cumulative event rainfall is significant, because this parameter could illustrate the impact of antecedent rainfall. It depicts that particular cumulative rainfall will saturate the soil layer within the specific interval, which eventually triggers the mass movement. The cumulative rainfall event, E, is determined as the accumulated rain from the beginning of rainfall to the precipitation that induces the slope failure.

Some authors applied this E-D threshold as the main threshold to predict the landslide, while others have established this threshold for secondary elements, despite the main I-D threshold (He et al., 2020; Lainas et al., 2016). He et al. (2020) carried out the study to develop both E-D and normalised $\mathrm{N}_{\mathrm{E}}-\mathrm{D}$ thresholds for the landslide in China using the quantile regression method and included the comparison between the I-D threshold around the globe as well to recognise the relation of the cumulative rainfall event and rainfall intensity.

Besides, the developed E-D thresholds apply different forms of equations. Firstly, most of the authors apply the power regression as similar to I-D threshold, which is:

$$
E=\alpha D^{-\gamma}
$$

Whereby cumulative rainfall event, $\mathrm{E}$ is measured in $(\mathrm{mm})$, rainfall interval, D is expressed either in (hour) or (day), while $\alpha$ and $\gamma$ are the coefficient of rainfall depth and the threshold 
inclination generated from the power-model regression, respectively. Meanwhile, Valenzuela et al. (2019) proposed the linear equation of E-D threshold in developing E-D threshold such as mentioned below:

$$
E+\alpha D=C
$$

Whereby cumulative rainfall event, $\mathrm{E}$ is measured in $(\mathrm{mm})$, and rainfall period, $\mathrm{D}$ is expressed either in (hour) or (day), while $\alpha$ and $\mathrm{C}$ are the slope value and y-intercept that comply with the linear relationship. Furthermore, Piciullo et al. (2016) utilised the E-D threshold for estimating the landslide in the Campania region, Italy. Using the Frequentist method for the statistical, empirical approach, that study managed to develop several thresholds using quantile regression method in accordance with the power-law equation of $\mathrm{E}$ $=\alpha \mathrm{D}^{-\gamma}$. On the basis of the comparison of several thresholds using the statistical percentile approach, the optimal rainfall threshold was applied to the early warning system by coordinating realtime rainfall with the pre-defined warning level thresholds.

Gariano et al. (2015) demonstrated a similar approach for the Sicily landslide, Italy. By performing the technique called consolidated bootstrap nonparametric to develop the E-D threshold, this approach could specify for different exceedance probability levels, and the uncertainty deduced from the threshold value. Moreover, by using that approach, The E-D threshold includes the standard deviation for the constant of $\alpha$ and $\gamma$, which are $\Delta \alpha$ and $\Delta \gamma$ to represent the uncertainty. According to Piciullo et al. (2016), the E-D threshold is newly defined as:

$$
E=\left(\alpha \pm \Delta \alpha \times D^{\gamma \pm \Delta \gamma}\right)
$$

Furthermore, by applying this E-D threshold, Melillo et al. (2018) managed to set up an application program called "Calculation of Thresholds for Rainfall-induced Landslides -Tool" (CTRLT) for automated rainfall threshold for the slope instability. Through the algorithm method, the reconstruction of a precipitation event, and modelling of various rainfall data, the E-D threshold is generated to predict the possibility of landslide.

The recent studies of rainfall thresholds focused more on the development of the E-D threshold than other types of rainfall thresholds (Abraham et al., 2020; Dikshit et al., 2019; He et al., 2020). Using cumulative rainfall event, $\mathrm{E}$ as the parameter to develop the rainfall threshold to perform the probabilistic model seems more convenient, compared to the analysing a specific rainfall event, as conducted for I-D threshold. This is because the error in probability and uncertainty is easier to determine using this threshold and the integration with the contingency of the landslide early warning system (Valenzuela et al., 2019).

\section{Normalized Cumulative Rainfall- Duration $\left(N_{E}-D\right)$ Threshold}

The role of normalising the cumulative event rainfall is to alleviate the uncertainties developed by the E-D threshold, since there are certain conditions where the cumulative rainfall event recorded a significantly lower amount of rainfall at the rain gauge located in close proximity of the landslide scene. Therefore, by rescaling the cumulative rainfall event, E with the mean Annual Precipitation (MAP), the developed normalised cumulative rainfall-duration $\left(\mathrm{N}_{\mathrm{E}}-\mathrm{D}\right)_{\mathrm{MAP}}$ threshold intends to represent the overall rainfall condition in the investigated area. This concept is more or less similar to the normalised I-D threshold, but comes with different rainfall parameters. The normalised $\left(\mathrm{N}_{\mathrm{E}}-\mathrm{D}\right)_{\text {MAP }}$ threshold is expressed as:

$$
N_{E}=\alpha D^{-\gamma}
$$

Whereby the normalised cumulative rainfall event, $\mathrm{N}_{\mathrm{E}}$ or $\mathrm{E}_{\mathrm{MAP}}$ is defined in ratio or (\%), while Duration, $\mathrm{D}$ is expressed in (hour) or (day). This normalised $\left(\mathrm{N}_{\mathrm{E}}-\mathrm{D}\right)_{\mathrm{MAP}}$ threshold demonstrates the percent of MAP that can determine the cumulative rainfall event which is likely to trigger the landslide. For instance, He et al. (2020) established a different set of rainfall thresholds for the rainy and non-rainy seasons in China. Likewise, Valenzuela et al. (2019) developed the normalised cumulative rainfall duration $\left(\mathrm{N}_{\mathrm{E}}-\mathrm{D}\right)$ for the Austria's region to acknowledge the comparison between the E-D thresholds from different meteorological stations and distinguish the variation of each threshold pertaining to regular rainfall received in each investigated region.

On the other hand, the dismissal of climatic factors is the main factor of normalising the accumulated rainfall with MAP. The geological, environmental, or anthropic factors contribute to landslides that have resulted in low threshold values (Valenzuela et al., 2019). The perception is relevant, but from a different point of view, 
the failure location might receive an abundance of rainfall during the event compared to the rain gauge that recorded a small amount of rainfall. Therefore, considering the MAP for normalising the rainfall is to portray the overall rainfall pattern of the area under study, which is in fact, associated with the impact of climate and the purpose of reducing the uncertainty and variation of cumulative rainfall.

\section{Rainfall Thresholds (R)}

The application of this so-called rainfall threshold ( $\mathrm{R}$ ) is not dominant, as compared to other thresholds (I-D, E-D, E-I). There are several parameters of rainfall that satisfy this rainfall threshold, such as intraday rainfall (R), cumulative rainfall event (E), antecedent precipitation (A), and rescaled cumulative event rainfall (Guzzetti et al., 2007). All these parameters are expressed in $(\mathrm{mm})$ except for rescaled cumulative event rainfall that are determined in ratio or percentage with respect to average yearly rainfall or MAP.

This approach merely considers the accumulated precipitation that is likely to trigger the landslide, which is quite impractical without involving the rainfall duration. The method used to obtain this rainfall threshold is unclear. The event precipitation may be calculated starting from rainfall event to the occurrence of landslide regardless of rainfall duration. Besides, the threshold is defined exactly by the precipitation amount, without any curve or threshold line generated from this type of application. For instance, if the cumulative rainfall event exceeds the certain amount of rainfall, a landslide can occur.

However, according to Guzzetti et al. (2007), the way to describe this type of threshold is by considering the percentage of mean annual precipitation rainfall (MAP). If the rainfall exceeds the range or specific percent of MAP, the measured rainfall may cause slope failure. This looks promising, since the rainfall threshold must be monitored with respect to MAP, rather than merely considering the accumulated precipitation.

From a different point of view, this application of rainfall threshold is somewhat flawed without the temporal element of rainfall duration. The impact of rainfall duration is critical, since it will determine the scale of the landslide. For example, the high amount of rainfall that is likely to trigger the soil slip or shallow landslide commonly happens for a short period of rainfall, while the low depth of rainfall with longer rainfall duration may induce the deep-seated landslide. Even though the rainfall threshold must be checked out with the MAP to determine the possibility of slope failure, the empirical correlation appears to be speculative. This rainfall threshold is probably related to the physical factor of the investigated area such as the geotechnical or morphological aspects.

\section{Cumulative Rainfall Event- Intensity (E-I) threshold}

The E-I threshold concept emphasises the relationship between the cumulative rainfall event, $\mathrm{E}$, and rainfall intensity (I). For instance, there is definite cumulative daily rainfall at a specific rainfall intensity that could trigger the landslide. This kind of threshold can be formed either for E-I or I-E threshold, subject to its dependent factor. If the intended graph requires a threshold for cumulative rainfall events, the E-I threshold will be considered and vice versa.

According to Guzzetti et al. (2007), Onodera et al. (1974) may be the one who initiated this type of threshold by presenting the quantitative rainfall-induced landslide using the parameters of the cumulative rainfall event $\mathrm{E}$ and the rainfall Intensity, I. The general E-I threshold is proposed as:

$$
E=\alpha I^{-\beta}
$$

The cumulative event precipitation, E, is expressed in $(\mathrm{mm})$, rainfall intensity, $I(\mathrm{~mm} / \mathrm{h})$, while $\alpha$ and $\beta$ are the constant regarding the power model relation. The inverse work applies on the I-E threshold where it will be defined as:

$$
I=\alpha E^{-\beta}
$$

On the other hand, some studies may apply a linear threshold in the Cartesian plane as the main threshold to estimate the landslide. For instance, in recent works, Huang et al. (2015) demonstrated the following equation to develop the rainfall threshold:

$$
R_{T}+\alpha I=C
$$

Whereby the cumulative event precipitation, $\mathrm{R}_{\mathrm{T}}$ or $\mathrm{E}$, is expressed in " $\mathrm{mm}$ ", while the rainfall intensity (I) in " $\mathrm{mm} / \mathrm{h}$ ", while $\alpha$ and $\mathrm{C}$ are 
the constants from the linear computation. From the developed E-I threshold, Huang et al. (2015) established a real-time warning system by classifying the graph according to the tendency line from different probability with respect to various colour-coded scale zone. Nevertheless, this E-I threshold is not widely established among the research, but still considered a legitimate rainfall threshold, since it can determine the ratio of the cumulative rainfall over the rainfall intensity or vice versa that are useful for predicting the occurrence of landslide.

Previously, Chien-Yuan et al. (2005) plotted the graph of the critical rainfall intensity against effective cumulative precipitation and come up with a specific rainfall amount that is likely to trigger the shallow landslide or debris flow at Taiwan. The authors mentioned that the $200 \mathrm{~mm}$ cumulative rainfall and the critical hourly intensity of $20 \mathrm{~mm}$ could induce the shallow landslide in the context of intermittent precipitation. Meanwhile, the effective cumulative rainfall that exceeds $400 \mathrm{~mm}$ could initiate the debris-flow during intense showers. However, there were no I-E thresholds discovered from the correlation. This indicates that the correlation of Event-Intensity or vice versa does not result in threshold development, instead of merely finalising the specific value of rainfall parameters regarding the perpendicular intersection.

\section{Other Thresholds Relation}

\section{Daily Rainfall versus Antecedent or vice versa}

Other than the earlier mentioned rainfall thresholds, several authors demonstrated the relation between intraday rainfall and the effective antecedent rainfall based on a few studies. The antecedent rainfall may influence the slope failures in the perspective of low matric suction and the rise in pore water pressure. For that reason, Ma et al. (2014) performed the relation between the calibrated antecedent rainfall for 10 days against the intraday rainfall at landslides. The rainfall threshold was established using the power law relation, and defined as:

$$
P o=\alpha P_{E A}^{-\beta}
$$

whereby the daily rainfall, Po is expressed in "mm", calibrated antecedent rainfall, $\mathrm{P}_{\mathrm{EA}}$ is expressed in "mm", while $\alpha$ and $\beta$ are the constants from the power law relation. According to the developed threshold of Ma et al. (2014), the intraday rainfall of beyond $30 \mathrm{~mm}$ could trigger the landslide after periods of sufficient antecedent precipitation. That means the lower daily rainfall can also trigger the landslide with the influence of antecedent rainfall.

On the other hand, Norsuzila et al. (2018) demonstrated the linear rainfall threshold according to the relation between 3-day and accumulated rainfall before landslide against 30 days cumulative antecedent precipitation. This proposed threshold is expressed as:

$$
E_{3}+\alpha E_{30}=C
$$

Whereby both 3-day cumulative precipitation, $\mathrm{E}_{3}$, while cumulative antecedent precipitation for 30 days, $\mathrm{E}_{30}$ are specified in "mm", while $\alpha$ and $\mathrm{C}$ are the constants from the linear computation. On the basis of the plot of 3-day accumulate rainfall before landslide against 30 days cumulative antecedent precipitation, the author performed two types of thresholds with regards to a different scale of landslide. For instance, the major landslide was obtained at the upper threshold, while the lower threshold was specified for the minor landslide.

Besides, the antecedent effect is also being considered as the extensive analysis for the developed rainfall threshold. The main objective of relating these two parameters is actually to determine the antecedent rainfall impact to the initiation of landslide. This relation of daily rainfall and antecedent rainfall are expressed in percent or ratio. For instance, Dahal and Hasegawa (2008) carried out the relation of daily rainfall of landslides and the cumulative rainfall before landslides $(3,7,10,14,20$, and 30 days $)$ to recognise the factor of the antecedent parameter. The diagonal line is plotted on the graph to determine the axis biased of the scattering in between the selected antecedent rainfall and daily rainfall and indicated the rainfall at the same value at the time of failure. If the plotted sample is biased towards the daily rainfall or y-axis, it means that the intraday precipitation has more impact on the landslide events. Otherwise, if the samples are plotted biasedly towards the $\mathrm{x}$-axis or selected day of the cumulative rainfall event, it indicates that the antecedent may influence the landslide. The 
analysis indicates that slope instability occurred due to preceding rainfall, since the obtained percentage for the effect of intraday rainfall against the 3 days cumulative rainfall is below 50 percent, as well declined for other cumulative 7 to 30 days before the landslides.

Kanungo and Sharma (2014) stated that minimum 10-day antecedent precipitation influenced the initiation of slope failure during the monsoon season at Chamoli-Joshimath region, India. On the other hand, Zêzere et al. (2005) proposed that the antecedent rainfall within 1-15 days could be categorised for the shallow landslips, while longer rainfall duration in between 1-3 months could lead to a deep-seated failure in Portugal. The difference in determining the effective antecedent rainfall for the slope instability at each region shows that incorporating such factors as morphology, geology, lithology, anthropic, etc., can crucially impact the occurrence of the landslide events.

\section{CONCLUSIONS}

The variety of rainfall calculations and analyses contributes an added value to the studies for developing the rainfall thresholds in predicting the landslide occurrence. This paper successfully comprehended the various rainfall parameters utilised in developing the rainfall threshold worldwide. Different rainfall thresholds have been discussed, namely Intensity-Duration (I-D), Cumulative Rainfall Event-Duration (E-D), Rainfall Intensity, (R), Cumulative Rainfall Event-Intensity (E-I), Normalised Intensity-Duration $\left(\mathrm{N}_{\mathrm{I}}-\mathrm{D}\right)$, Normalised Cumulative Event-Duration $\left(\mathrm{N}_{\mathrm{E}}-\mathrm{D}\right)$ and antecedent rainfall thresholds. These various rainfall thresholds require critical methods and analysis to derive the rainfall parameters. It entirely depends on the authors' critical thinking for selecting the most compatible method within the study limitations. Although there is a variety of methods to develop the rainfall threshold, the main goal is to undertake risk mitigation against the dreadful impact of landslide through the integrated warning system. More findings are supposed to be discovered in the future to enhance and sustain the conceptual framework of rainfall threshold.

\section{Acknowledgments}

The research was carried out under Fundamental Research Grant Scheme (FRGS-RACER) project RACER/1/2019/TK01/UIAM//1 provided by the Ministry of Education of Malaysia.

\section{REFERENCES}

1. Abraham M.T., Satyam N., Pradhan B., Alamri A.M. 2020. Forecasting of landslides using rainfall severity and soil wetness: A probabilistic approach for Darjeeling Himalayas. Water (Switzerland), 12(3).

2. Aleotti P. 2004. A warning system for rainfallinduced shallow failures. Engineering Geology, 73(3-4), 247-265.

3. Brunetti M., Peruccacci S., Rossi M., Luciani S., Valigi D., Guzzetti F. 2010. Rainfall thresholds for the possible occurrence of landslides in Italy. Natural Hazards and Earth System Sciences, 10, 447-458.

4. Caine N. 1980. The rainfall intensity-duration control of shallow landslides and debris flows. Geografiska Annaler, 62(1-2), 23-27.

5. Campbell R.H. 1975. Soil Slips, Debris Flows, and Rainstorms in the Santa Monica Mountains and Vicinity, Southern California. US Government Printing Office, 851, 1-51.

6. Cannon S.H., Gartner J.E., Wilson R.C., Bowers J.C., Laber J.L. 2008. Storm rainfall conditions for floods and debris flows from recently burned areas in southwestern Colorado and southern California. Geomorphology, 96(3-4), 250-269.

7. Chen C.W., Saito H., Oguchi T. 2015. Rainfall intensity-duration conditions for mass movements in Taiwan. Progress in Earth and Planetary Science, 2(14).

8. Chien-Yuan C., Tien-Chien C., Fan-Chieh Y., WenHui Y., Chun-Chieh, T. 2005. Rainfall duration and debris-flow initiated studies for real-time monitoring. Environmental Geology, 47(5), 715-724.

9. Crozier M.J. 1997. The climate-landslide couple: a southern hemisphere perspective. In: Matthews JA, Brunsden D, Frenzel B, Gläser B, Weiß MM (Eds) Rapid mass movement as a source of climatic evidence for the Holocene. Gustav Fischer, Stuttgart, 333-354.

10. Dahal R.K., Hasegawa S. 2008. Representative rainfall thresholds for landslides in the Nepal Himalaya. Geomorphology, 100(3-4), 429-443.

11. Dikshit A., Sarkar R., Pradhan B., Acharya S., Dorji K. 2019. Estimating rainfall thresholds for landslide occurrence in the Bhutan Himalayas. Water (Switzerland), 11(8). 
12. Endo T. 1969. Probable distribution of the amount of rainfall causing landslides, Annual Report 1968, Hokkaido Branch, For. Exp. Stn., Sapporo, 122-136.

13. Gabet E.J., Burbank D.W., Putkonen J.K., PrattSitaula B.A., Ojha T. 2004. Rainfall thresholds for landsliding in the Himalayas of Nepal. Geomorphology, 63(3-4), 131-143.

14. Garcia-Urquia E. 2016. Establishing rainfall frequency contour lines as thresholds for rainfall-induced landslides in Tegucigalpa, Honduras, 19802005. Natural Hazards, 82(3), 2107-2132.

15. Gariano S.L., Brunetti M.T., Iovine G., Melillo M., Peruccacci S., Terranova O., Guzzetti F. 2015. Calibration and validation of rainfall thresholds for shallow landslide forecasting in Sicily, southern Italy. Geomorphology, 228, 653-665.

16. Giannecchini R., Galanti Y., Avanzi G.D.A. 2012. Critical rainfall thresholds for triggering shallow landslides in the Serchio River Valley (Tuscany, Italy). Natural Hazards and Earth System Sciences, 12, 829-842.

17. Guzzetti F., Peruccacci S., Rossi M., Stark C.P. 2007. Rainfall thresholds for the initiation of landslides in central and southern Europe. Meteorology and Atmospheric Physics, 98(3-4), 239-267.

18. Guzzetti F., Peruccacci S., Rossi M., Stark C.P. 2008. The rainfall intensity - duration control of shallow landslides and debris flows: an update. Landslides, 5, 3-17.

19. Habibah L., Lea T.T., Khan Y.A., Kamil A.A., Nazirah A. 2013. Prediction of landslide using Rainfall Intensity-Duration Threshold along East-West Highway, Malaysia. Proc. AWAM International Conference on Civil Engineering \& Geohazard Information Zonation Prediction, 124-133.

20. He S., Wang J., Liu S. 2020. Rainfall event-duration thresholds for landslide occurrences in China. Water (Switzerland), 12(2).

21. Huang J., Ju N.P., Liao Y.J., Liu D.D. 2015. Determination of rainfall thresholds for shallow landslides by a probabilistic and empirical method. Natural Hazards and Earth System Sciences, 15(12), 2715-2723.

22. Huang X. \& Tang C. 2014. Formation and activation of catastrophic debris flows in Baishui River basin, Sichuan Province, China. Landslides, 11(6), 955-967.

23. Jibson R. 1989. Debris flow in southern Puerto Rico. Geological Society of America, Special Paper, 236, 29-55.

24. Kazmi D., Qasim S., Harahap I.S.H., Baharom S., Imran M., Moin S. 2016. A Study on the Contributing Factors of Major Landslides in Malaysia. Civil Engineering Journal, 2(12), 669-678.
25. Kanungo D.P. \& Sharma S. 2014. Rainfall thresholds for prediction of shallow landslides around Chamoli-Joshimath region, Garhwal Himalayas, India. Landslides, 11(4), 629-638.

26. Lainas S., Sabatakakis N., Koukis G. 2016. Rainfall thresholds for possible landslide initiation in wildfireaffected areas of western Greece. Bulletin of Engineering Geology and the Environment, 75(3), 883-896.

27. Lazzari M. \& Piccarreta M. 2018. Landslide disasters triggered by extreme rainfall events: The case of montescaglioso (Basilicata, Southern Italy). Geosciences (Switzerland), 8(10).

28. Leonarduzzi E., Molnar P., McArdell B.W. 2017. Predictive performance of rainfall thresholds for shallow landslides in Switzerland from gridded daily data. Water Resources Research, 53(8), 6612-6625.

29. Ma T., Li C., Lu Z., Wang B. 2014. An effective antecedent precipitation model derived from the power-law relationship between landslide occurrence and rainfall level. Geomorphology, 216, 187-192.

30. Marchi L., Arattano M., Deganutti A.M. 2002. Ten years of debris-flow monitoring in the Moscardo Torrent (Italian Alps). Geomorphology, 46, 1-17.

31. Marques R., Zêzere J., Trigo R., Gaspar J., Trigo I. 2008. Rainfall patterns and critical values associated with landslides in Povoação County (São Miguel Island, Azores): relationships with the North Atlantic Oscillation. Hydrological Process, 22, 478-494.

32. Melillo M., Brunetti M.T., Peruccacci S., Gariano S.L., Roccati A., Guzzetti F. 2018. A tool for the automatic calculation of rainfall thresholds for landslide occurrence. Environmental Modelling and Software, 105, 230-243.

33. Napolitano E., Fusco F., Baum R.L., Godt J.W., De Vita P. 2016. Effect of antecedent-hydrological conditions on rainfall triggering of debris flows in ash-fall pyroclastic mantled slopes of Campania (southern Italy). Landslides, 13(5), 967-983.

34. Nikolopoulos E.I., Crema S., Marchi L., Marra F., Guzzetti F., Borga M. 2014. Impact of uncertainty in rainfall estimation on the identification of rainfall thresholds for debris flow occurrence. Geomorphology, 221, 286-297.

35. Nolasco-Javier D. \& Kumar L. 2017. Deriving the rainfall threshold for shallow landslide early warning during tropical cyclones: a case study in northern Philippines. Natural Hazards, 90(2), 921-941.

36. Norhidayu K., Kamarudin A.T., Wan Nur Aifa W.A., Norfarah Nadia I., Nadiah M.H., Ahmad Bukhari R. 2020. Rainfall intensity-duration induced debris flow in Peninsular Malaysia. Proc. of AICCE'19.

37. Norsuzila Y., Tajudin N., Azita Laily Y., Darmawaty M.A., Suzi Seroja, S. 2018. Rainfall thresholds for possible landslide occurrence in Ulu Kelang, Selangor, Malaysia using TRMM satellite precipitation 
estimates. IOP Conference Series: Earth and Environmental Science, 169.

38. Onodera T., Yoshinaka R., Kazama H. 1974. Slope failures caused by heavy rainfall in Japan. Proc. 2nd International Congress of the Int. Ass. Eng. Geol. San Paulo, 1-10.

39. Peruccacci S., Brunetti M.T., Gariano S.L., Melillo M., Rossi M., Guzzetti F. 2017. Rainfall thresholds for possible landslide occurrence in Italy. Geomorphology, 290, 39-57.

40. Piciullo L., Gariano S.L., Melillo M., Brunetti M.T., Peruccacci S., Guzzetti F., Calvello M. 2016. Definition and performance of a threshold-based regional early warning model for rainfall-induced landslides. Landslides, 14(3), 995-1008.

41. Reichenbach P., Cardinali M., De Vita P., Guzzetti F. 1998. Regional hydrological thresholds for landslides and floods in the Tiber River Basin (central Italy). Environmental Geology, 35(2-3), 146-159.

42. Saito H., Nakayama D., Matsuyama H. 2010. Relationship between the initiation of a shallow landslide and rainfall intensity-duration thresholds in Japan. Geomorphology, 118(1-2), 167-175.

43. Segoni S., Piciullo L., Gariano S.L. 2018. A review of the recent literature on rainfall thresholds for landslide occurrence. Landslides, 15(8), 1483-1501.

44. Shakya B. 2002, A new approach within hydrometeorological technique for the estimation of average depth of probable maximum precipitation (PMP) over Nepal. Wu, et al.(Ed.), Flood Defence; 599-606.
45. Uchida T., Okamoto A., Kanbara J., Kuramoto K. 2013. Rainfall thresholds for deep-seated rapid landslides. Italian Journal of Engineering Geology and Environment, 211-217.

46. Valenzuela P., Zêzere J.L., Domínguez-Cuesta M.J., Mora García M.A. 2019. Empirical rainfall thresholds for the triggering of landslides in Asturias (NW Spain). Landslides, 16(7), 1285-1300.

47. Vaz T., Zêzere J.L., Pereira S., Oliveira S.C., Garcia R.A.C., Quaresma I. 2018. Regional rainfall thresholds for landslide occurrence using a centenary database. Natural Hazards and Earth System Sciences Discussions, 18, 1037-1054.

48. Yang H., Wei F., Ma Z., Guo H., Su P., Zhang S. 2020. Rainfall threshold for landslide activity in Dazhou, southwest China. Landslides, 17(1), 61-77.

49. Zêzere J.L., Trigo R.M., Trigo I.F. 2005. Shallow and deep landslides induced by rainfall in the Lisbon region (Portugal): assessment of relationships with the North Atlantic Oscillation. Natural Hazards and Earth System Science, 5(3), 331-344.

50. Zêzere J.L., Vaz T., Pereira S., Oliveira S.C., Marques R., Garcia R.A.C. 2015. Rainfall thresholds for landslide activity in Portugal: a state of the art. Environmental Earth Sciences, 73(6), 2917-2936.

51. Zhou W. \& Tang C. 2014. Rainfall thresholds for debris flow initiation in the Wenchuan earthquakestricken area, southwestern China. Landslides, 11(5), 877-887. 